\title{
Assessing amount of physical activity in childhood: comparison of a questionnaire and objectively measured physical activity for children in Gateshead Millennium Study
}

\author{
Laura Basterfield $^{1}$, Ashley Adamson ${ }^{1}$, Kathryn Parkinson ${ }^{1}$, Ulrike Maute ${ }^{2}$, Pei Xin-Li ${ }^{2}$ and John Reilly ${ }^{2}$ \\ ${ }^{1}$ Newcastle University, Newcastle upon Tyne, UK and ${ }^{2}$ University of Glasgow, Glasgow, UK
}

Level of habitual moderate-vigorous intensity physical activity (MVPA) may have a major influence on fatness in UK children and adolescents $^{(1)}$. Current public health surveillance of children's level of MVPA is based on data collected using a non-validated questionnaire (Health Survey for England; $\mathrm{HSE}^{(2)}$ ). The aim was to validate this questionnaire in a subset of 6-7 year olds in the Gateshead Millennium Study, a birth cohort of 1029 children in north-east England born between June 1999 and May 2000 ${ }^{(3)}$.

The HSE questionnaire (completed by parents) was used to estimate habitual MVPA in 130 children (sixty-four boys and sixty-six girls), whilst simultaneous objective measurements were made for $7 \mathrm{~d}$ using an Actigraph GT1M accelerometer (Actigraph LLC, Pensacola, FL, USA). The children were asked to wear the accelerometer during waking hours for $7 \mathrm{~d}$, excluding water-based activities. Parents were asked to record on a simple diary the times when the belt was worn. Information from the accelerometer was analysed to ascertain time spent in MVPA using published cut-offs ${ }^{(4)}$.

Mean MVPA (min/d) as estimated by the questionnaire was 146 (95\% CI 124, 169) and 24 (95\% CI 22, 26) when measured by the accelerometer (Figure). The mean difference in relation to that measured by the questionnaire was 122 (95\% CI 124, 169) min/d. There was no significant rank order correlation between MVPA measured by the two methods.

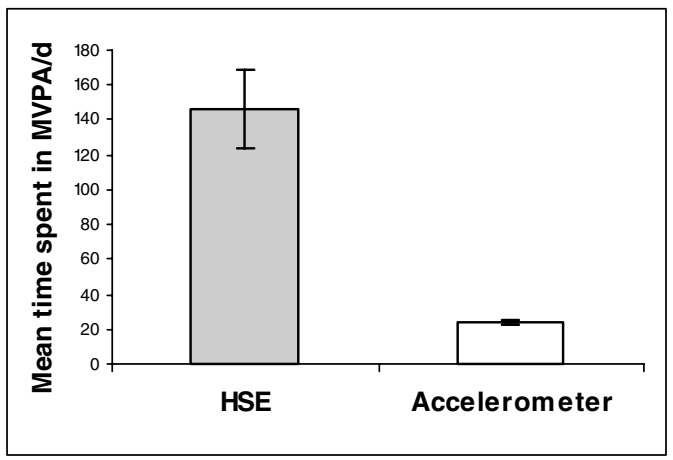

Figure. Daily amount of MVPA taken by the children using the two methods.

The HSE questionnaire substantially overestimated the amount of time children spent in MVPA and did not rank them in relation to their physical activity level. Another method of public health surveillance of children's physical activity is warranted.

This work was funded by the National Prevention Research Initiative (NPRI), a funding initiative of UK government departments, research councils and medical charities (see www.npri.org.uk).

1. Ness AR, Leary SD, Mattocks C et al. (2007) PLoS Med 4, e97.

2. Sproston K \& Primatesta P (editors) (2003) Health Survey for England 2002. London: The Stationery Office

3. The Gateshead Millennium Study Team (2008) The Gateshead Millennium Study. www.ncl.ac.uk/gms/

4. Puyau MR, Adolph AL, Vohra FA \& Butte NF (2002) Obes Res 10, 150-157. 